Type of the Paper (Article)

\title{
Combined Use of Ultrasonic Pulse Velocity and Rebound Hammer for Structural Health Monitoring of Reinforced Concrete Structures
}

\author{
Ahmed Lasisi ${ }^{1}$, Obanishola Sadiq ${ }^{2}$ and Ibrahim Balogun ${ }^{2, *}$ \\ 1 University of Delaware; aolasisi@udel.edu \\ 2 University of Lagos; iobalogun@unilag.edu.ng \\ * Correspondence: aolasisi@unilag.edu.ng
}

\begin{abstract}
This work investigates the use of Non-destructive tests as a tool for monitoring the structural performance of concrete structures. The investigation encompassed four phases; the first of which involved the use of destructive and non-destructive mechanisms to assess concrete strength on cube specimens. The second phase research focused on site assessment for a twin engineering theatre located at the Faculty of Engineering, University of Lagos using rebound hammer and ultrasonic pulse velocity tester. The third phase was the use of linear regression analysis model with MATLAB to establish a relationship between calibrated strength as well as ultrasonic pulse velocities with their corresponding compressive strength values on cubes and values obtained from existing structures. Results show that the root-mean squared- $\mathrm{R}^{2}$ values for rebound hammer ranged between $\mathbf{0 . 2 7 5}$ and $\mathbf{0 . 7 4 2}$ while ultrasonic pulse velocity $\mathrm{R}^{2}$ values were in the range of 0.649 and 0.952 for air curing and water curing systems respectively. It initially appeared that the Ultrasonic pulse velocity was more suitable for predicting concrete strength than rebound hammer but further investigations showed that the latter was adequate for early age concrete while the former was more suited for aging concrete. Hence, a combined use is recommended in this work.
\end{abstract}

Keywords: Non-Destructive Tests, Structural Health Monitoring, Ultrasonic Pulse Velocity, Rebound Hammer, Surface Hardness, Compressive Strength, Linear regression

\section{Introduction}

The incidence of structural collapse in sub-Saharan Africa especially the most populous and industrial cities in these region has been a major source of concern. Building collapses ranging from residential buildings to churches and other public structures is almost a normal phenomenon in dense cities like Lagos, Dares-salaam, etc. Most of the collapses in Lagos have however been attributed to structural defect[1]. Of these structural defects, material components especially concrete plays a major role since it constitutes the greatest percentage of reinforced concrete structures. Improper mix ratios, poor building material specifications, inadequate supervision amongst others are key factors contributing to this menace[2]. The only reliable known method of assessing structural strength of concrete members have always been the destructive tests. The development of many nondestructive techniques, many of them enabling quick measurements at reduced cost, has opened ways for progress. A recent study has shown how these techniques can be used for helping the engineer to better assess the material condition, the geometry of the structure, or the development of deterioration. The results showed the established models on structural components give rise to a better estimation of the in-situ concrete strength as compared to cube specimens.[3]

Concrete specifications usually vary from prescribed mixes to designed mixes. Each offering its inherent shortcomings are usually abused even by unskilled workmen who mostly jeopardize any form of standardization in concrete preparation. This leads to serious variability in the quality of 
concrete produced after hardening. Cube samples are easily estimated in the laboratory. Concrete members on site can only be estimated except through non-destructive techniques. Hence, the primary objective of this paper is to sufficiently predict the degree of reliability of the too commonest NDTs in sub-Saharan Africa (Rebound Hammer and Ultrasonic Pulse velocity) as a suitable replacement for estimating in-situ strength of concrete members instead of adopting other semidestructive methods like the pull-out tests amongst others. We therefore demonstrate a combine use in this paper.

\subsection{Rebound Hammer Test}

Per the relevant British Standard for surface hardening test, the testing of concrete by hardness methods is not generally considered to be a substitute for other well established methods, but only as a useful preliminary or complementary method, Hardness measurements provide information on the quality of the surface layer (about $30 \mathrm{~mm}$ deep) of the concrete only. The attention of the user is drawn to the fact that the devices give a measure of the surface hardness of the concrete only, and that the relationship to any other property of the concrete is empirical. No single correlation with strength or any other measurable property applies to all concrete, and a calibration for a specific set of circumstances is necessary if acceptable accuracy is to be obtained. It is unlikely that $95 \%$ confidence limits on the estimation of the strength of concrete in situ will be better than $+25 \%$ under ideal conditions. The use of universal calibrations, such as those produced by the manufacturers of rebound hammers, can lead to serious errors, and should be avoided.

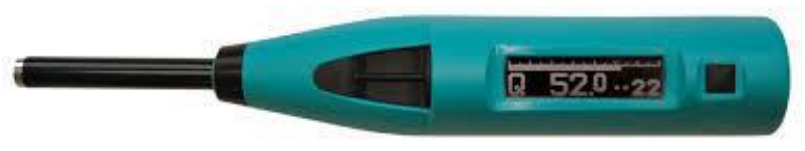

Figure 1: A digital Schmidt Rebound Hammer [Photo Credit: Proceq]

The rebound hammer is one of the most popular nondestructive testing methods used to investigate concrete. Its popularity is due to its relatively low cost and simple operating procedures. The rebound hammer is also one of the easiest pieces of equipment to misuse; thus, many people do not trust the rebound test results.[4]

\subsection{Ultrasonic Pulse Velocity Test}

Among the available methods of NDT, the UPV methods can be considered as one of most promising methods for evaluation the concrete structures, once it makes possible an examination of the material homogeneity. It is possible to obtain a total control of a structure, using the properties variations with the time. Using the analysis of the propagation variations of ultrasonic velocity wave, it is possible to verify the compactness or detect heterogeneous regions in the concrete.[5] 


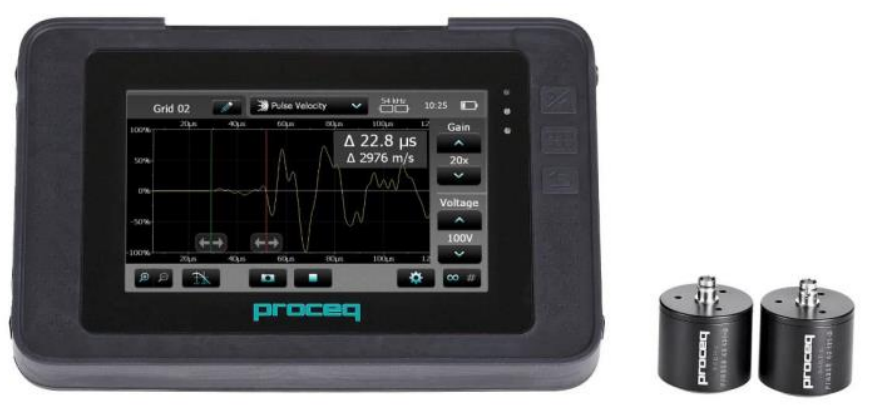

Figure 2: An Ultrasonic Pulse Velocity Tester-Pundit Device [Photo Credit: Proceq]

The method is normally based on the use of portable equipment, composed by the source/detector unit and the surface transducers, which works in the frequency range of 25 to $60 \mathrm{kHz}$. The ultrasonic pulses depend on the density and elastic properties of the material. The methodology of UPV is based at time monitoring of pulses in a section of the object. The UPV will depend on the density and the elastic properties of the material in study. The quality of many materials of construction is related with its rigidity, the measure of the UPV can be used to measure the concrete structures quality, estimate the mechanical properties, the compressive strength and the modulus of elasticity.

The tests begin when an ultrasonic pulse is generated and transmitted for an electroacoustic transducer, placed in contact with the surface of concrete. After to pass the concrete, the vibrations are received and converted by the electro-acoustic transducer. The passed time between input and output of the wave is measured with precision of at least $0,1 \mu \mathrm{s}$. The sounds which are produced at one environment might be reflected or reverberated into the surrounding surfaces, and these sounds can still be transmitted to other environments. Phenomena like this are the basis of ultrasonic methods in materials.[6] Operation is relatively straightforward but requires great care if reliable results are to be obtained. One essential is good acoustical coupling between the concrete surface and the face of the transducer, and this is provided by a medium such as petroleum jelly, liquid soap or grease. Air pockets must be eliminated, and it is important that only a thin separating layer exists any surplus must be squeezed out. A light medium, such as petroleum jelly or liquid soap, has been found to be the best for smooth surfaces, but a thicker grease is recommended for rougher surfaces which have not been cast against smooth shutters. If the surface is very rough or uneven, grinding or preparation with plaster of Paris or quick-setting mortar may be necessary to provide a smooth surface for transducer application.[4]

Transducer arrangement: There are three basic ways in which the transducers may be arranged, as shown in Figure 2.4. These are: (i) Opposite faces (direct transmission) (ii) Adjacent faces (semi-direct transmission) (iii) Same face (indirect transmission). 


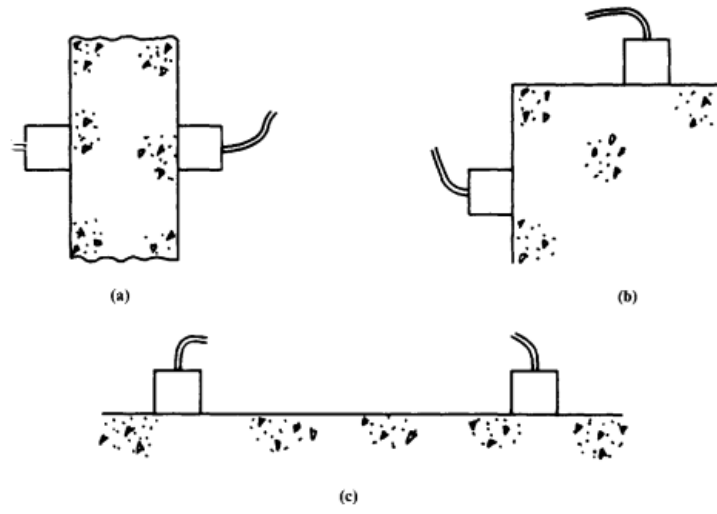

Figure 3: Transducer Arrangement [Photo Credit: Hall,1991]

Since the maximum pulse energy is transmitted at right angles to the face of the transmitter, the direct method is the most reliable from the point of view of transit time measurement. Also, the path is clearly defined and can be measured accurately, and this approach should be used wherever possible for assessing concrete quality. The semi-direct method can sometimes be used satisfactorily if the angle between the transducers is not too great, and if the path length is not too large. The sensitivity will be smaller, and if these requirements are not met it is possible that no clear signal will be received because of attenuation of the transmitted pulse.[7]

Therefore, this research work has been conducted using the direct method to forestall any inaccuracies that could arise because of the indirect or semi-direct methods.

\section{Experimental Methodology}

The object of this research study is to formulate a correlation between rebound hammer method, ultrasonic pulse velocity and the compression method using different curing methods and assessing in-service structure as well as structures under construction for monitoring structural health. To obtain these results, it is required to perform a series of tests on specimen in the laboratory. Notable amongst these were the determination of the physical properties of the aggregates and binders to be used, workability and setting time tests on the plastic mixes (varying percentage replacements values), compressive tests, nondestructive tests (rebound hammer and UPV) on the hardened mixes under different curing conditions. Other preliminary tests include specific gravity and density. On site procedures were also carried out on the Engineering auditorium for in-service and underconstruction observations.

For the laboratory samples, materials were characterized, graded and analyzed. The fine aggregate used in this research study was river-sand obtained from Ogun River bed located at Ibafo town in Ogun state. It was confirmed to be salt free not like sand gotten from the lagoon whose salt content is high. The sand particles were sieve which was free from clay, loam, dirt and organic or chemical matter of any description. The particles that pass-through BS sieve No. 4 (aperture $2.36 \mathrm{~mm}$ ) but retained on sieve No 220 (aperture $0.06 \mathrm{~mm}$ ) ensuring that the dust particles were removed from the sand. The coarse aggregate used were crushed granite of igneous origin. They come in different sizes but the recommended size is in the range $12.5 \mathrm{~mm}$ to $19 \mathrm{~mm}$ to attain the target strength for the Julius Berger Auditorium. The cement used was Ordinary Portland cement (Lafarge Portland Cement). This cement satisfies international standards on cement (BS 12 Portland Cement). It ensures that the 
cement passes test for which its properties maybe determined such as soundness, consistency, setting times, etc. An admixture was also employed to accelerate strength development of concrete to the targeted strength of the structures examined in-situ. The admixture used for the purpose of this research is the Master Rheobuild 850. Water used for curing and casting was potable and did not contain any traces of sulphates, ferrites, alkaline, oils, vegetation or salt that could impact the properties of the materials or concrete in the fresh or hardened state (Annex A of BS 3148:1980)

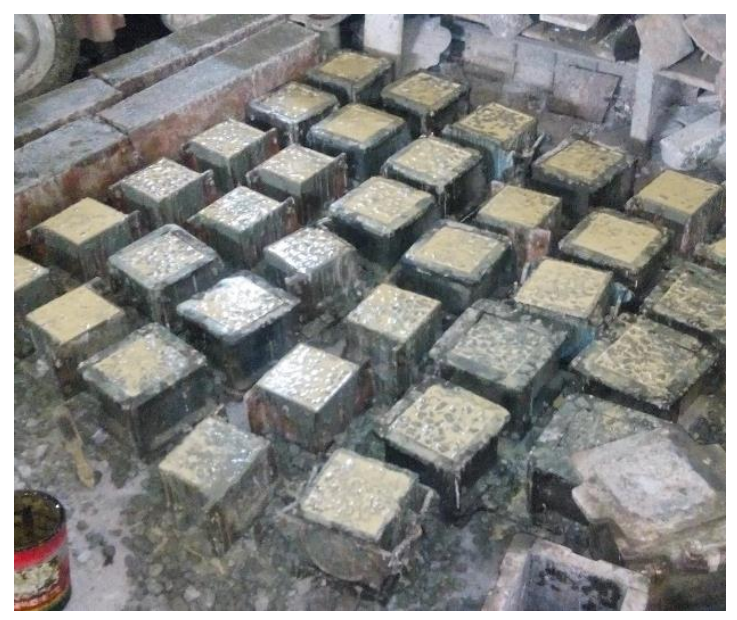

Figure 4: Concrete cubes in molds after casting and before demolding.

\subsection{Mixing and Casting}

Concrete constituents were mixed in a revolving drum mixer for approximately Ten minutes at an average speed of 32rpm till uniformity was attained in the concrete matrix. Steel molds of (150 by 150 by $150 \mathrm{~mm}$ ) were filled with fresh concrete in approximately three equal strata and thoroughly compacted with a tamping rod. Mixing and casting are in accordance with the recommendations provided in BS 1881 Pt. 125 and BS 1881 Pt. 108.

\subsection{Curing Systems}

The curing methods employed are:

1. Water (Moist) Curing: Cubes were left in the laboratory for approximately 24 hours after casting before they were demolded. After demolding, cube specimens were introduced into curing tanks filled with potable water as described above. Curing was carried out at approximately $20^{\circ} \mathrm{C}$ and a relative humidity of about $92 \%$.

2. Air (Dry) Curing: To successfully simulate site conditions, concrete is usually exposed to air-drying conditions after 7 days of routine wetting. Hence, $50 \%$ of concrete cubes cured in the tank were exposed to normal ambient conditions after 7 days at a temperature of about $28^{\circ} \mathrm{C}$ and relative humidity of about $72 \%$.

\subsection{Apparatus, Tools and Equipment}

These include an Avery weighing machine of about $50 \mathrm{~kg}$ capacity, cube moulds made of cast-iron with inner dimensions of 150x150x150mm, a slump mould, concrete mixer, vicat's apparatus, a power operated hydraulic destructive compression testing machine, wheel barrow, tapping rod, standard sieve sizes, rebound hammer, ultrasonic pulse velocity tester amongst others.

\subsection{Casting Schedule}


For the laboratory exercise, the casting schedule adopted is provided in Table 1. Compressive strength was carried out at 7, 14, 21, 28 and 56 days respectively from the day of casting for both air and water curing specimens. The concrete specimens were standard $150 \mathrm{~mm}$ cube specimens to BS 1881-3:1970.

Table 1: Curing Schedule for Cubes Cast and Tested

\begin{tabular}{|c|c|c|c|}
\hline \multirow{2}{*}{ Water/binder ratio } & \multicolumn{2}{|c|}{ Number of Curing Samples } \\
\cline { 2 - 4 } & Age of Concrete & WATER CURING & AIR CURING \\
\hline \multirow{2}{*}{0.35} & 7 & 50 & - \\
\hline & 14 & 20 & 20 \\
\hline 21 & 10 & 10 \\
\hline & 56 & 5 & 5 \\
\hline
\end{tabular}

Three specimens for each series were crushed to failure using a $1500 \mathrm{kN}$ capacity compression machine. The average compressive strength of the three test specimens was computed to report the compressive strength of the concrete used in the research. Also, three specimens each of the exposure regimes were tested at 7(only water curing) and 14,21, 28, 56 days for both curing methods to serve as control specimens for the compressive strength. The test was carried out in accordance with BS 1881-116: 1983.

\subsection{Presentation of Selected Sites}

After Laboratory experiments, we also carried out investigation on the sites shown in figure 5:
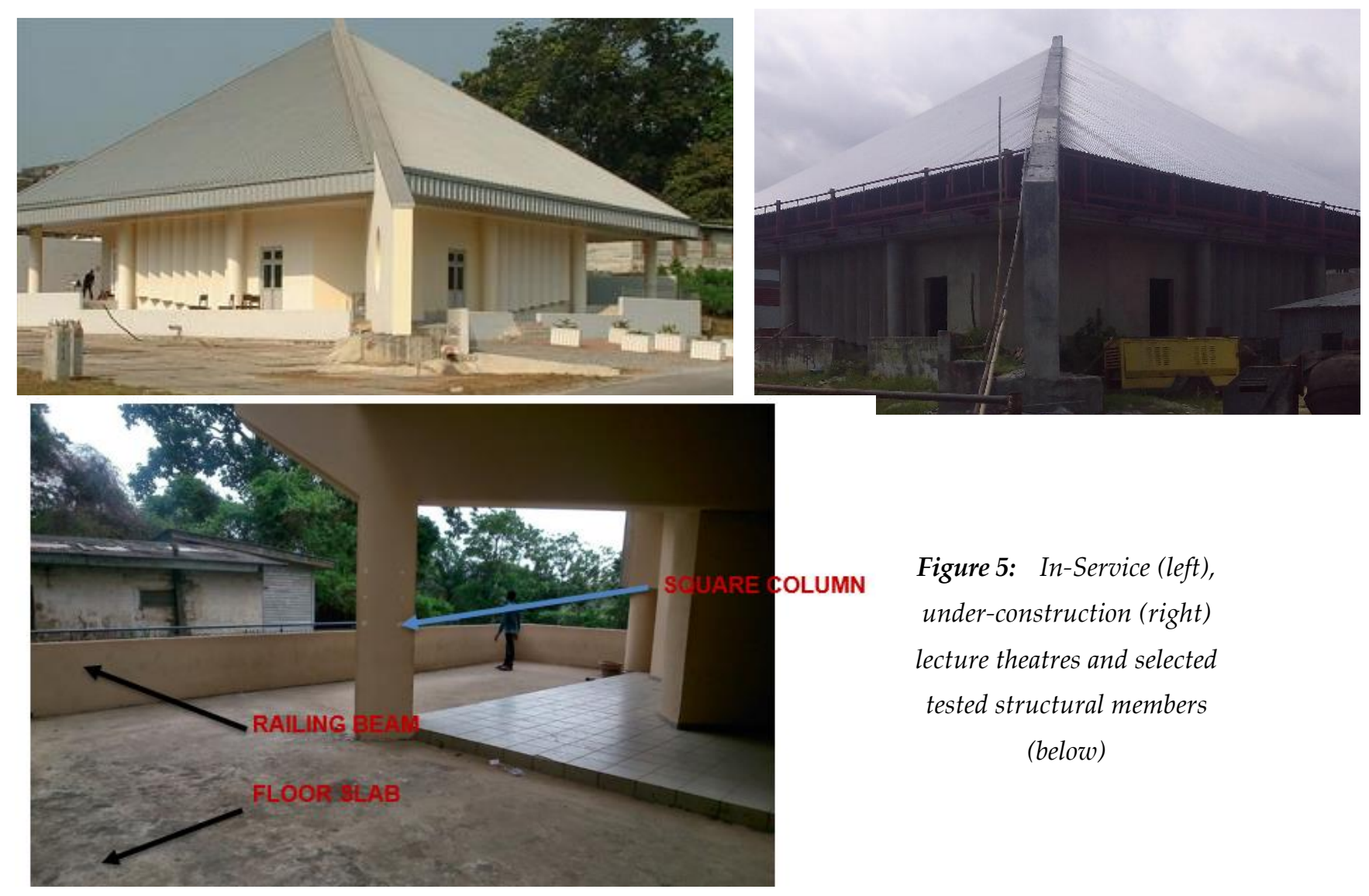

Figure 5: In-Service (left), under-construction (right) lecture theatres and selected tested structural members (below) 

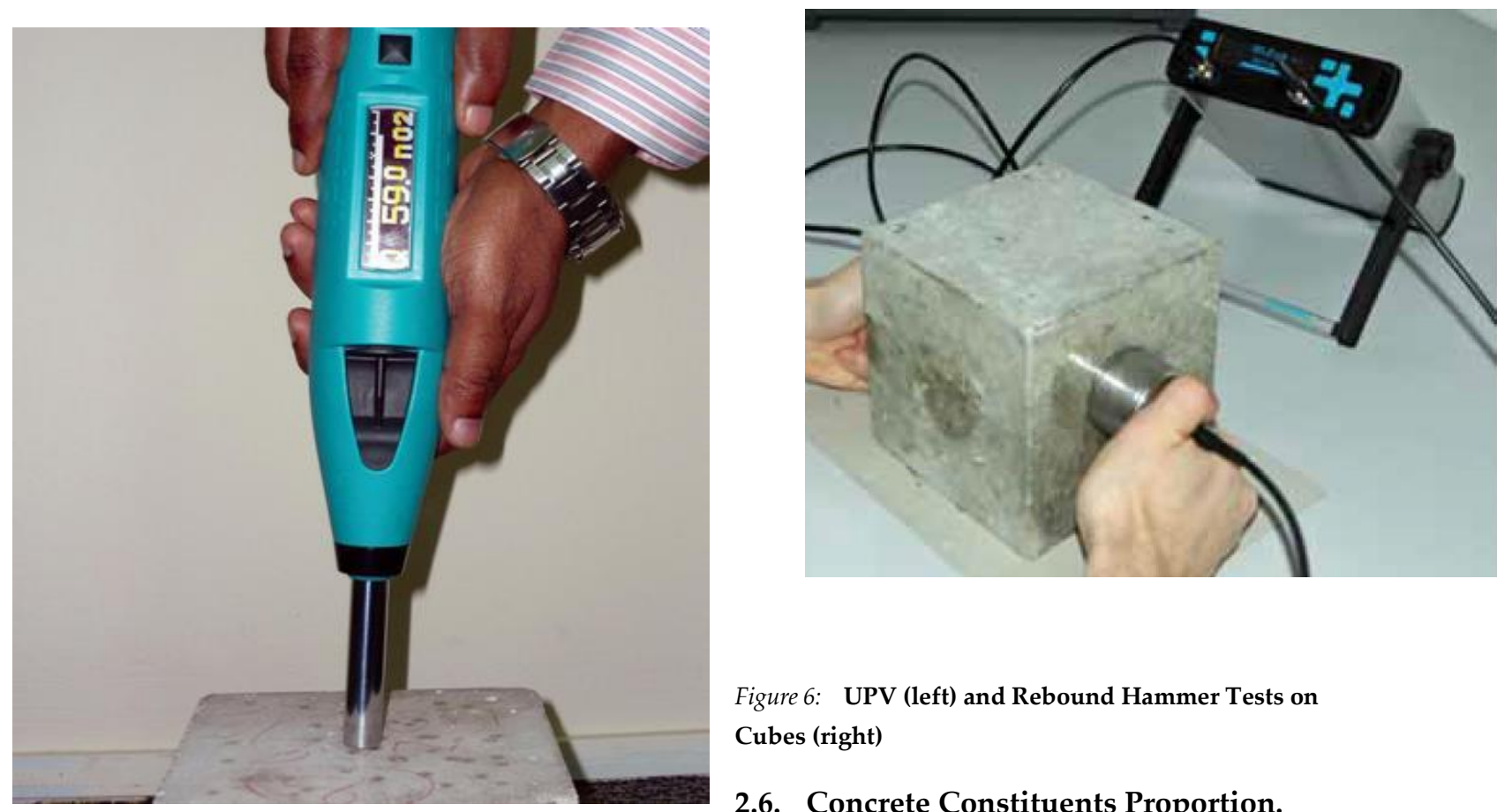

Figure 6: UPV (left) and Rebound Hammer Tests on Cubes (right)

2.6. Concrete Constituents Proportion.

A mix design was carried out and the following constituents were estimated for a concrete grade M50 with which the presented structures are built:

Table 2: Sizes of different concrete constituents

\begin{tabular}{|c|c|c|c|}
\hline S/NO & CONCRETE CONSTITUENT & \multicolumn{1}{c}{ RATIO } & TOTAL WEIGHT \\
\hline $\mathbf{1 . 0}$ & CEMENT & $1 / 4.29$ & $76.769 \mathrm{~kg}$ \\
\hline $\mathbf{2 . 0}$ & FINE AGGREGATE & $0.83 / 4.29$ & $65.13 \mathrm{Kg}$ \\
\hline 3.0 & C. AGGREGATE & $2.47 / 4.29$ & $185.65 \mathrm{~kg}$ \\
\hline $\mathbf{4 . 0}$ & WATER & $0.35 \mathrm{~W} / \mathrm{C}$ & $26.86 \mathrm{~kg}$ \\
\hline $\mathbf{5 . 0 .}$ & ADMIXTURE & $1.2 \% \mathrm{CMNT}$ & $0.921 \mathrm{~kg}$ \\
\hline
\end{tabular}

\section{Results}

It is essential to illustrate relationships between NDT and the standard compressive test of the same concrete specimens as well as in-situ values. Detailed description of the concrete mix has been provided in the table above. The total volume of concrete used for laboratory experiments was to the tune of $0.135 \mathrm{~m}^{3}$. A summary of preliminary and tertiary tests conducted will be provided below:

\section{PHYSICAL PROPERTIES:}

Particle size gradation and distribution is as provided in the chart below: 


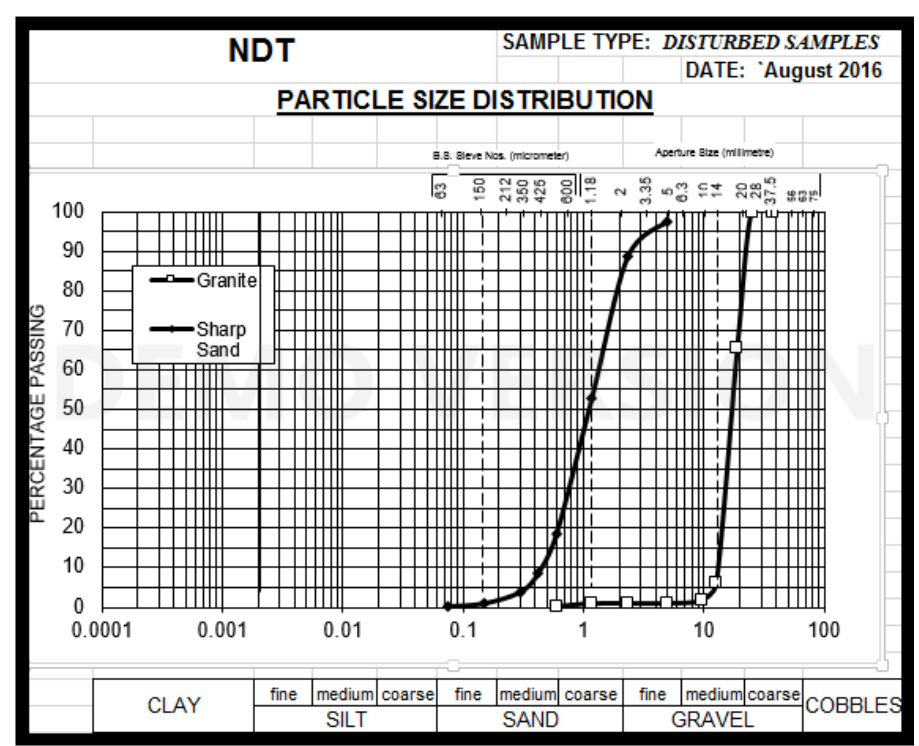

Figure 6: Particle Size Distribution Curve for Sand and Granite

Per Unified Soil Classification, the fine aggregates are classified as gap-graded medium to coarse sand while the coarse aggregates are gap-graded granite.

For Sand;

$$
\begin{aligned}
& \mathrm{Cu}=\frac{1.4}{0.425}=3.29 \\
& \mathrm{CC}=\frac{1 \times 1}{1.4 \times 0.425}=1.68
\end{aligned}
$$

For Gravel;

\begin{tabular}{|c|c|c|}
\multicolumn{2}{|c}{} & $\mathrm{Cu}=\frac{20}{14}=1.43$ \\
& Sand & $\mathrm{CC}=\frac{17 \times 17}{20 \times 14}=1.03$ \\
\hline $\mathrm{D}_{10}$ & $\mathbf{0 . 4 2 5}$ & $\mathbf{1 4}$ \\
\hline $\mathrm{D}_{30}$ & $\mathbf{1 . 0}$ & $\mathbf{1 7}$ \\
\hline $\mathrm{D}_{60}$ & $\mathbf{1 . 4}$ & $\mathbf{2 0}$ \\
\hline
\end{tabular}

Table 3: $D_{10}, D_{30}$ and $D_{60}$ values for aggregates 
The setting times of the cement used are as characterized as shown in Table 4 below:

Table 4: Some Physical Properties of Aggregates and Cement

\begin{tabular}{|c|c|c|}
\hline Start Time & $12: 35 \mathrm{pm}$ & Duration \\
\hline Initial Setting & $1: 55 \mathrm{pm}$ & 1Hrs 20Mins \\
\hline Final Setting & $\mathbf{5 : 3 0 p m}$ & 3Hrs 35Mins \\
\hline
\end{tabular}

Other physical properties tests show that sand, gravel and cement had specific gravities of 2.50, 2.76 and 3.15 respectively. Table 5 is a summary of all physical properties

Table 5: Characterization of Cement Setting

\begin{tabular}{|c|c|c|c|}
\hline PHYSICAL PROPERTY & SAND & GRANITE & CEMENT \\
\hline $\begin{array}{c}\text { FINES CONTENT (\% passing } \\
\text { through } 600 \mu \mathrm{m} \text { sieve) }\end{array}$ & - & - & 99.5 \\
\hline $\begin{array}{l}\text { UNIFORMITY COEFFICIENT } \\
\qquad(\mathrm{Cu})\end{array}$ & 2.73 & 1.43 & - \\
\hline $\begin{array}{l}\text { COEFFICIENT OF } \\
\text { CURVATURE }(\mathbf{C z}) \\
\end{array}$ & 0.73 & 1.03 & - \\
\hline SPECIFY GRA VITY & 2.50 & 2.76 & 3.15 \\
\hline DRY DENSITY (Kg/m3) & 1248.31 & 1102.86 & - \\
\hline
\end{tabular}

\subsection{Discussion}

The following charts have been adopted for the conversion of rebound numbers and ultrasonic pulse velocities based on proven trend observed in these physical quantities. 


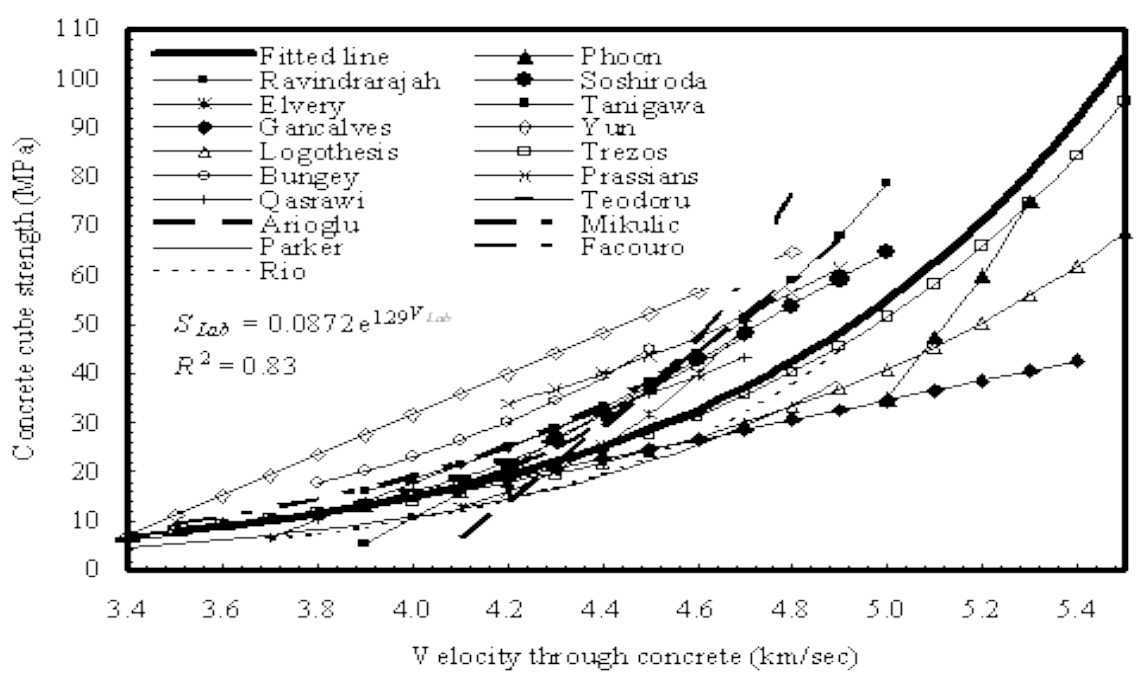

Figure 7: Calibration Curves for UPV (Source: [8])

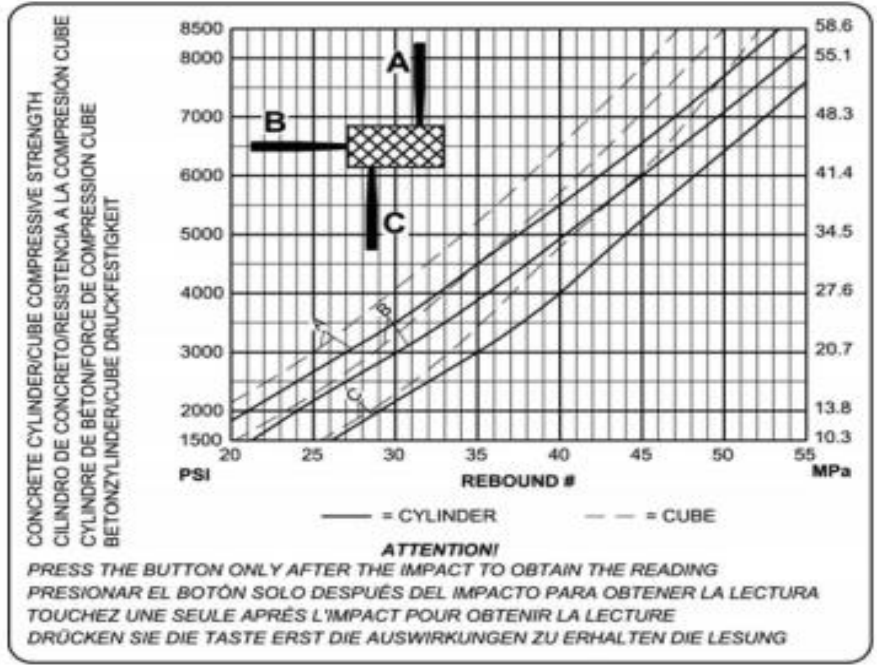

Figure 8: Calibration Curves for Rebound Hammer (Source:[9])

With a focus on concrete strength alone, we employed Rebound Hammer Test (RHT) and Ultrasonic Pulse Velocity (UPV) test results as the NDT comparatives to the conventional laboratory crushing values and then observed how it varied over time. The research is constitutive of both laboratory and computational components. It tested for the extent to which these two NDTs can either be applied independently or collectively to assess the compressive strength of concrete using existing structures and concrete specimens in the laboratory. 


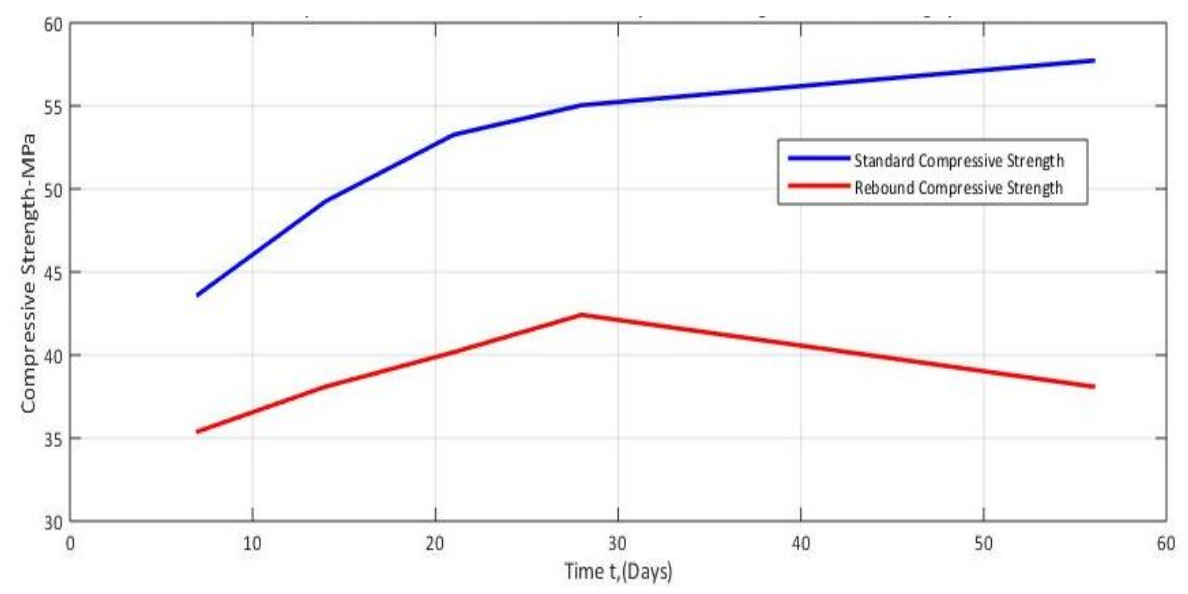

Figure 9: Strength Development as observed by Rebound

\section{Hammer and Destructive Tests-Water Cured}

The above shows an $\mathrm{R}^{2}=0.275$ which is an indication of a weak correlation between rebound number and compressive strength for water-cured specimens. However, this seeming lack of correlation stemmed from the relatively low rebound number at 56 days compared to the compressive strength. It is a further indication that the reliability of rebound hammer reduces as the age of concrete increases. Below is the regression analysis excluding the 56 days' result. It is quite clear that this gives a better correlation; $\mathrm{R}^{2}=0.916$.

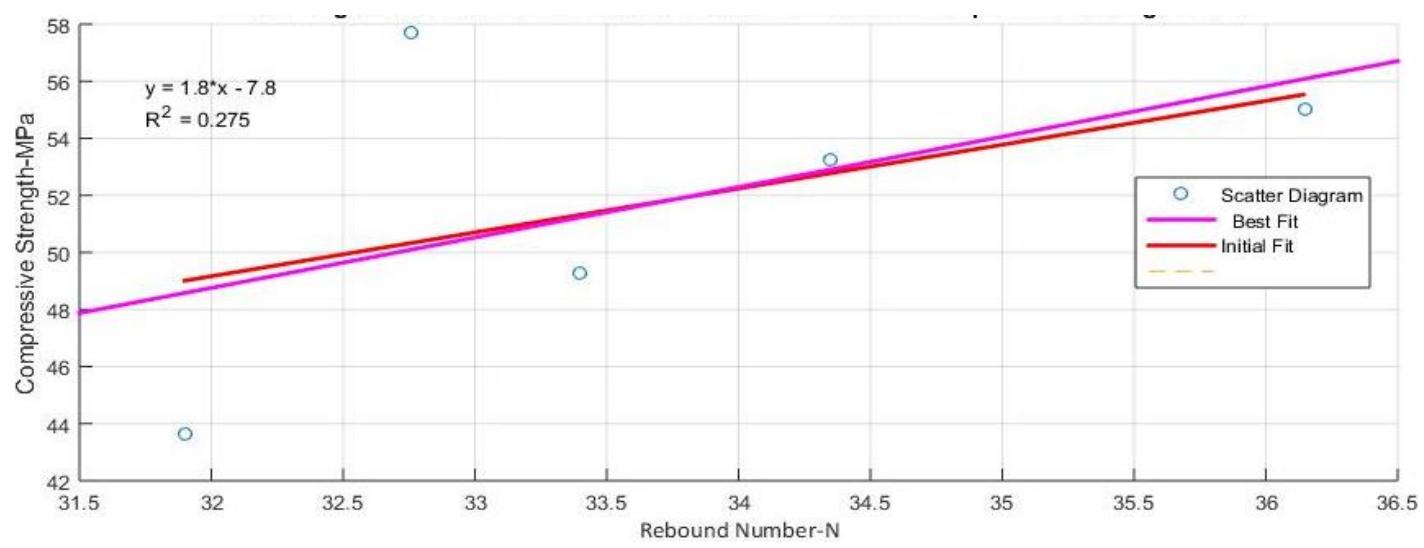




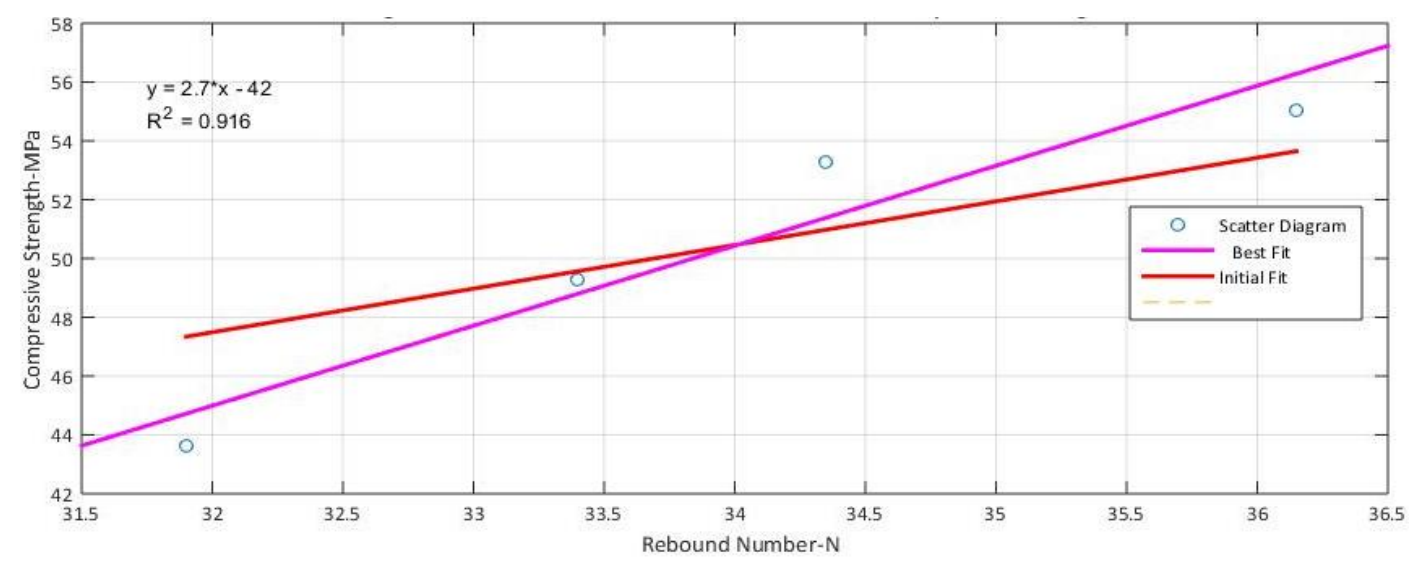

Figure 10: a. Regression plot for Rebound Hammer (Uncorrected), Regression plot for Rebound Hammer (Corrected)

It is obvious from the above that the ultrasonic pulse velocity converted values (based on the charts provided in Figure 7) gives a lower early age correlation compared to the latter days. One may therefore hypothesize that UPV may be more suitable for aged concrete testing. We can test this hypothesis as we shall soon see. The above also shows an $\mathrm{R}^{2}=0.649$ which is an indication of a fairly strong correlation between ultrasonic pulse velocity and compressive strength for air-cured specimens. The same observation was made for water-cured samples as shown in Figure 12 but the degree of variation will be assessed for the regression graph in Figure 13. The correlation graph shows $\mathrm{R}^{2}=0.952$ which is an indication of an extremely strong correlation between ultrasonic pulse velocity and compressive strength for water-cured specimens. This is the most positive correlation observed so far. It therefore hints that water cured specimen may probably be best observed using the Pundit Equipment rather than Rebound Hammer. The 28-day strength for the water curing system is $89 \%$ of the 28th day strength which is just $1 \%$ less than the standard. However, this is not the same for the air curing system which is $105.6 \%$. This abnormal. In short, the water curing system gives a better strength development pattern closer to conventional concrete strength pattern that the air curing system. Figure $\mathbf{1 4}$ below shows a haphazard strength development during the early age of concrete after which a sharp drop was noticed. This drop here when compared to past work in Figure $\mathbf{1 5}$ shows that air cured concrete loses strength over time while a more comprehensive study carried out at the state of Illinois shows that this drop was later succeed by an increase in strength as shown in Figure 16. Hence, our results for UPV above show a similar agreement to the two observations when 
combined while Rebound Hammer show a lower estimate but a similar pattern was still observed. Generally, the table below shows that generally, rebound hammer values are mostly below the M50 Grade for both the new and old auditoria. It is therefore fair enough to conclude at this stage that the rebound hammer is not a good assessment tool for aging concrete.

Except a proper calibration method is devised, the assumption holds at least for the set of values presented in this research work. Ultrasonic pulse velocity values however are fairly adequate for both auditoria except for column strength for new auditorium with values on the borderline which are expected to increase in strength with time. One may therefore conclude that the Ultrasonic Pulse Velocity method is very adequate for long term concrete measuring, hence for structural health monitoring. 

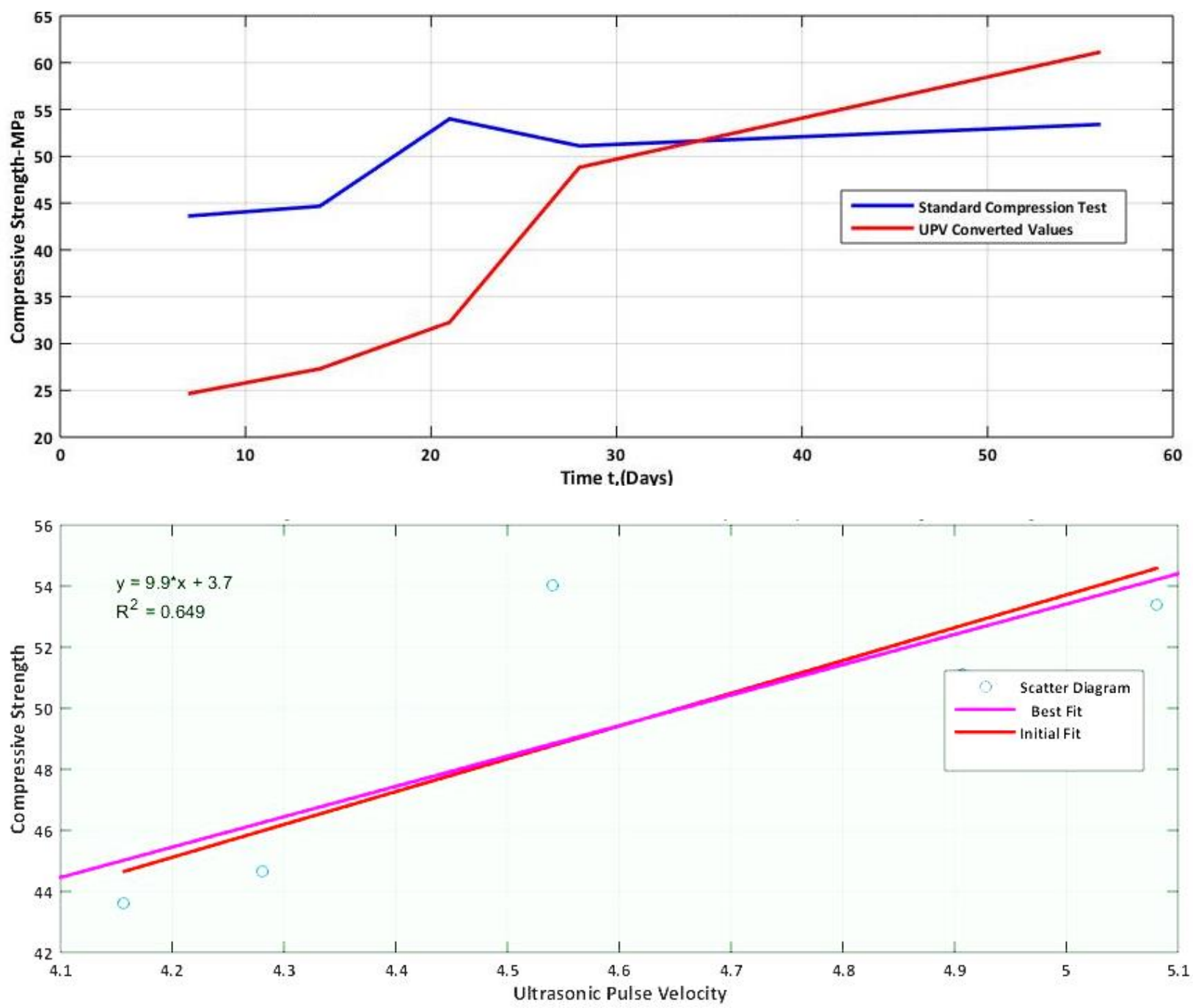

Figure 11: a. Strength Development and Correlation Chart for Ultrasonic Pulse Velocity-Air (Top), b. Relationship between UPV-converted and Standard Crushing Values for Air Curing Specimens (Bottom 


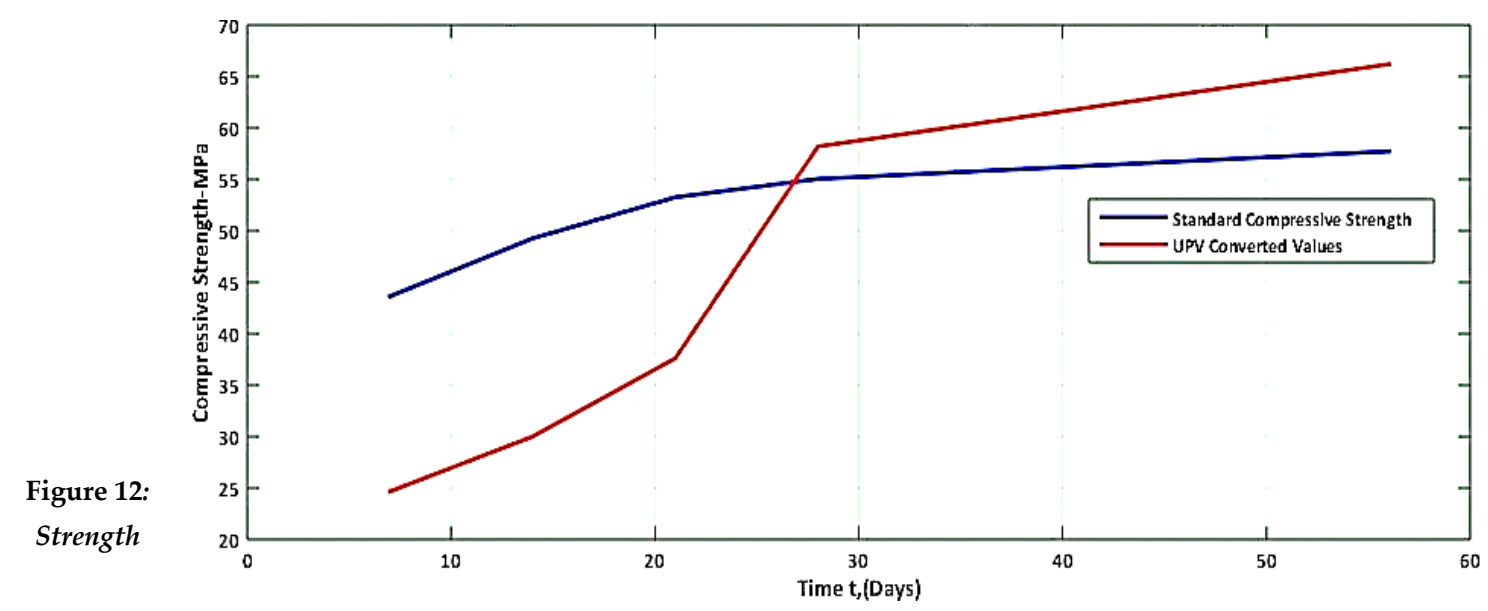

Development Chart for Ultrasonic Pulse Velocity Standard Compressive Test-Water cured

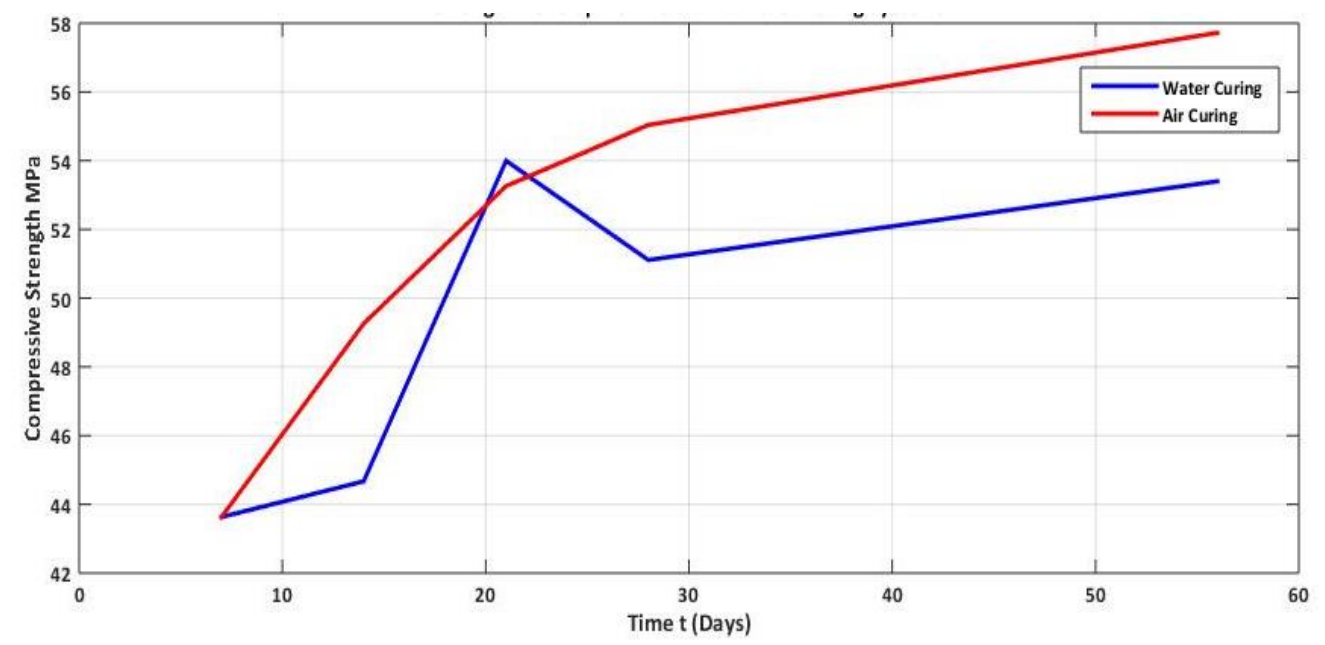

Figure

13: Comparison of Air Curing and Water Curing Results for Standard Strength Gain

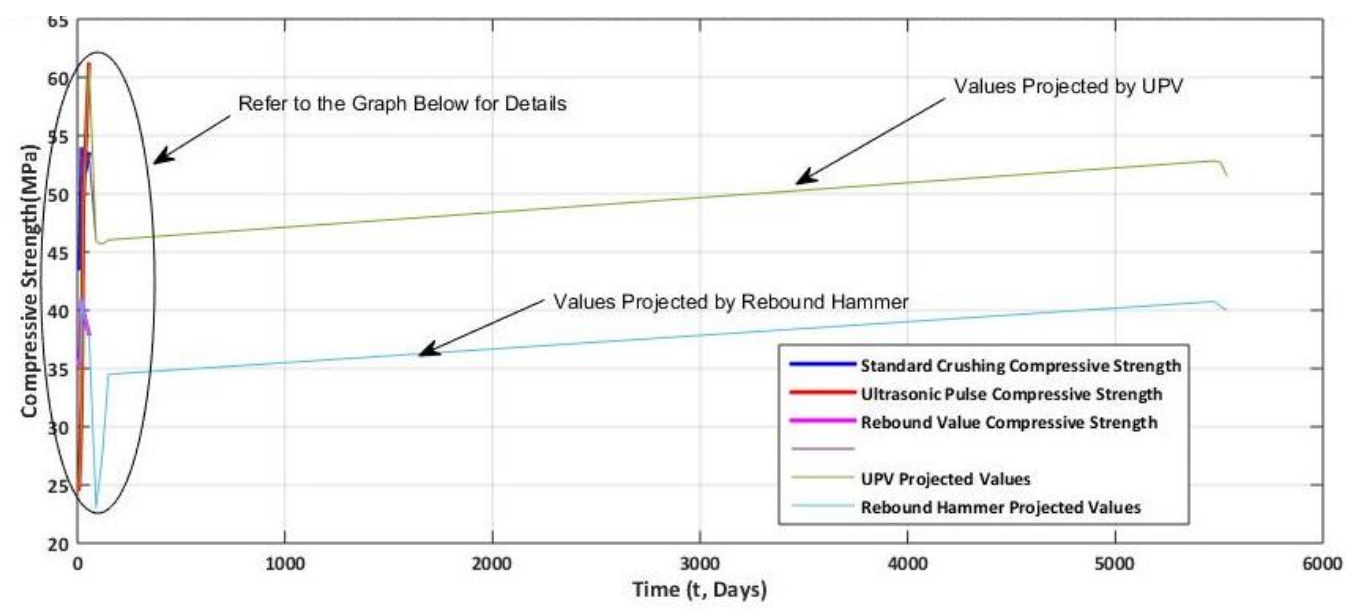

Figure 14: Projection of Current Strength (UPV, RN AND ACV) Values to Future Terms (0-15 Years)-above For Air Curing System Based On Test Results-LHS 


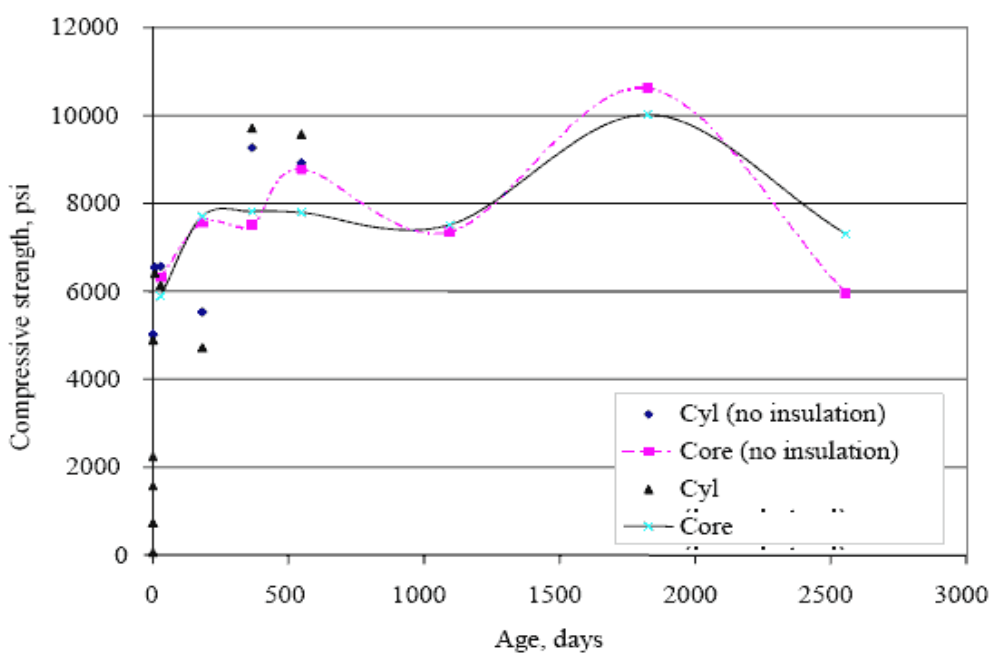

Figure 15:

Time and Compressive Strength Gain(Source: [10])

Moist Curing

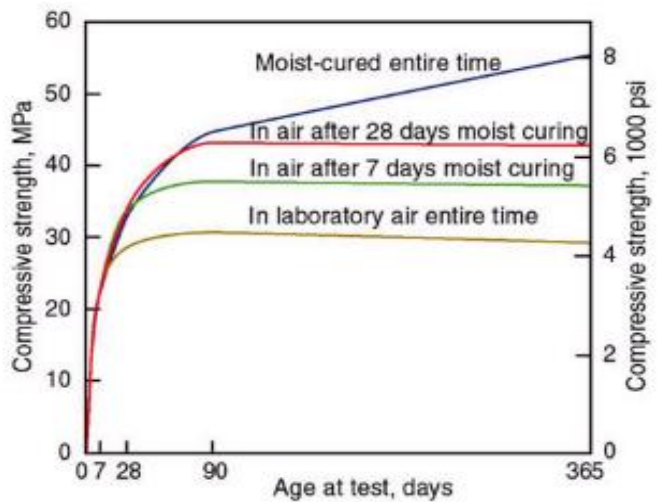

Figure 16: Graph of Compressive Strength vs age for test site in Illinois(Source: [11])

\begin{tabular}{|c|c|c|c|c|c|c|c|c|c|}
\hline \multirow{2}{*}{ THEATRE } & & \multicolumn{4}{|c|}{$\begin{array}{l}\text { ULTRASONIC PULSE } \\
\text { VELOCITY VALUES(MPa) }\end{array}$} & \multicolumn{4}{|c|}{$\begin{array}{l}\text { REBOUND HAMMER } \\
\text { STRENGTH VALUES(MPa) }\end{array}$} \\
\hline & & $\begin{array}{l}\theta \\
\text { COL. }\end{array}$ & COL. & BEAM & SLAB & $\begin{array}{l}\theta \\
\text { COL. }\end{array}$ & COL. & BEAM & SLAB \\
\hline \multirow[t]{3}{*}{ IN-SERVICE } & APRIL & 53.14 & 52.51 & 46.12 & 58.25 & 41.5 & 40.0 & 32.0 & 44.0 \\
\hline & MAY & 52.05 & 53.25 & 47.11 & 57.75 & 41.2 & 33.67 & 34.5 & 44.0 \\
\hline & JUNE & 51.24 & 51.75 & 49.83 & 57.72 & 38.0 & 42.0 & 34.0 & 46.0 \\
\hline \multirow{3}{*}{$\begin{array}{l}\text { UNDER- } \\
\text { CONSTRUCTION }\end{array}$} & APRIL & 46.45 & 45.34 & 61.68 & 52.61 & 26.0 & 20.0 & 52.0 & 30.0 \\
\hline & MAY & 48.76 & 42.56 & 59.01 & 52.62 & 34.0 & 21.0 & 48.0 & 34.0 \\
\hline & JUNE & 44.78 & 47.31 & 58.99 & 53.78 & 33.0 & 36.0 & 42.0 & 46.0 \\
\hline
\end{tabular}

Note: $\theta C O L$.: Circular Column while the other is a 600 by 600 square column. Red inked values are values below M50 grade./

Figure 17: Tabular Comparison Between Ultrasonic Pulse Velocities Values of Compressive Strength and Rebound Hammer Converted Values for Old and New JB

\section{Conclusion}

From the analysis and validation of existing model, $\mathrm{R}^{2}$ values which range between $\mathbf{0 . 2 7 5}$ and $\mathbf{0 . 7 4 2}$ for rebound hammer shows an inconsistent correlation when compared to ultrasonic pulse velocity root mean squared values of $\mathbf{0 . 6 4 9}$ and $\mathbf{0 . 9 5 2}$ for air curing and water curing respectively. Although, water curing gave a better correlation than air curing, the air curing system most accurately represent 
site condition where concrete is usually not cured beyond a week of casting. Also, predicted values of today's early age strength development skewed better in favor of Ultrasonic Pulse velocity than Rebound hammer. However, observation shows that rebound hammer is well suited for early age assessment than ultrasonic pulse velocity.

One may therefore conclude that a combined use of pundit and rebound hammer as Non-destructive test methods for assessment of both early age and aging concrete will give more desirable results than each used in isolation. However, the Ultrasonic Pulse velocity equipment stands a better chance as a tool for structural health monitoring; though relatively more expensive.

Lastly, while past research work shows sufficient correlation between rebound number and compressive strength, the concrete assessed were of low grade. However, low correlations have been observed in this investigation for high strength concrete.

\section{Acknowledgement}

This work has been done through the collaborative efforts of selfless individuals. Appreciation goes to the technicians at the University of Lagos Structures Lab who gave us the needed support to get this job done. I will be ungrateful if I do not appreciate the management of Ove Arup Lagos office for availing us their PROCEQ PUNDIT EQUIPMENT which was used for the Ultrasonic Pulse Velocity Test. We also appreciate EDX for providing us with the student license we got through their "Elements of Structures MIT Online course" which was eventually used to access Math Works MATLAB for modelling and computational works. You guys have all been wonderful.

\section{References}

[1] A. Alexander and A. Rufus, "Assessment of Building Collapse in Nigeria : A Case of Naval Building , Abuja , Nigeria," vol. 2, no. 4, pp. 584-591, 2012.

[2] I. Chendo I.G, Obi, "BUILDING COLLAPSE IN NIGERIA : THE CAUSES , EFFECTS , CONSEQUENCES AND REMEDIES . Assoc . Prof I . G Chendo and Arc . N . I . Obi University of Nigeria, Enugu Campus. ABSTRACT : Building collapses in Nigeria have been on the increase in recent times. T," vol. 3, no. 4, pp. 41-49, 2015.

[3] M. Ghrici, "ANALYSIS OF THE RELATIONSHIP BETWEEN NONDESTRUCTIVE AND DESTRUCTIVE TESTING OF LOW CONCRETE STRENGTH IN NEW STRUCTURES," vol. 18, no. 2, pp. 191-205, 2017. 
[4] C. \& Hall, "The ultrasonic pulse velocity method," Chapman Hall, vol. 24, pp. 267-268, 1991.

[5] A. Lorenzi, F. T. Tisbierek, L. Carlos, and S. Filho, "Ultrasonic Pulse Velocity Analysis in Concrete Specimens 2 . Concrete Evaluation considering Nondestructive Testing," 2007.

[6] A. Lorenzi, L. Carlos, S. Filho, L. S. Lorenzi, R. Shimomukay, and J. A. Chies, "5th Pan American Conference for NDT Monitoring Concrete Structures through UPV Results and Image Analysis," no. October, 2011.

[7] L. A. Oluwafemi, "HAMMER ) AS A TOOL FOR STRUCTURAL HEALTH MONITORING," no. 80402023, 2016.

[8] F. Aydin and M. Saribiyik, "Correlation between Schmidt Hammer and destructive compressions testing for concretes in existing buildings," Sci. Res. Essays, vol. 5, no. 13, pp. 1644-1648, 2010.

[9] J. Helal, M. Sofi, and P. Mendis, "Non-Destructive Testing of Concrete: A Review of Methods," Electron. J. Struct. Eng., vol. 14, no. 1, pp. 97-105, 2015.

[10] P. (WA) By Jerzy Z. Zemajtis, Ph.D., “Role of Concrete Curing,” 2008. [Online]. Available: http://www.cement.org/for-concrete-books-learning/concrete-technology/concreteconstruction/curing-in-construction.

[11] FHWA US, "Highway Concrete Technology Development and Testing Volume IIi: Field Evaluation of SHRP C-205 Test Sites (High Performance Concrete)," 2006. [Online]. Available: http://www.fhwa.dot.gov/publications/research/infrastructure/pavements/pccp/02084/refere nce.cfm. 